\title{
Moda e estilo: introdução a uma estética da moda*
}

\begin{abstract}
RESUMO
A recepção e a produção são dois aspectos da problemática estética que vamos tentar explorar neste ensaio, enfatizando sobretudo o aspecto da produtividade, com a contribuição de autores como Luigi Pareyson $(1993,1989)$ da mesma forma que pretendemos enfatizar a aproximação entre estético e artístico, a partir das consideraçõees de John Dewey (1974). Certamente que outros autores nos guiarão na tentativa de explicitar a associação emblemática entre recepção e produção na moda, sobretudo por conta da dimensão de artisticidade presente neste fenômeno.
\end{abstract}

\section{PALAVRAS-CHAVE}

moda

estético

formatividade

\section{ABSTRACT}

The reception and the production are two aspects of the aesthetic problematic that we try to explore in this essay, emphasizing the aspect of productivity, with the contribution of authors suches as Luigi Pareyson $(1993,1989)$ in the same way that we intend to emphasize the approach between aesthetic and artistic, from the considerations of John Dewey (1974). Certainly that other authors will guide us in the attempt of setting out the emblematic association between reception and production in fashion, over all because of the dimension of present art in this phenomenon.

\section{KEY WORDS}

fashion

aesthetic

style
A exposição Shoes, de 147 pares de sapato da estilista britânica Vivienne Westwood (criadora do estilo punk na moda) chamou a atenção de milhares de espectadores durante a $24^{\text {a }}$ São Paulo Fashion Week (SPFW), que ocorreu entre 17 e 21 de janeiro, no espaço da Bienal, em São Paulo. Além da exposição, cerca de 40 desfiles, das mais renomadas marcas, integraram esta edição do evento que mostrou as tendências para o inverno de 2008, sob o tema "Diversidade e o lugar do indivíduo em meio à confusão do dia-a-dia nos grandes centros". Muitos foram os flahs, e os espaços ocupados pela SPFW nos mais variados meios de comunicação: revistas, blogs, portais, jornais, telejornais... enfim, todos tiveram em suas pautas a cobertura deste grande evento de moda do país. E muitos foram aqueles que tomaram conhecimento das novas tendências para o inverno 2008. Mesmo os mais refratários aos assuntos da toilette foram atingidos, de algum modo, pela moda. É assim que pelo menos duas vezes ao ano, através de grandes eventos de lançamento, a moda se torna tema e objeto de atenção.

Aparentemente, todos esses fatos referem-se à experiência da moda em sua dimensão receptiva. Em certa medida isto é verdade, mas o que se consome nesses eventos é menos uma possibilidade vestimentar concreta do que a idéia mesma da moda enquanto um mundo o mundo fashion -, apresentado como um espetáculo destinado à pura contemplação. Contudo, crer que o verdadeiro receptor da moda está aí nos conduziria a estabelecer uma relação muito direta entre moda e arte, mas a preço de ignorar justamente $\mathrm{o}$ aspecto vestimentar em que ela se ancora e que se traduz em nossa sociedade numa prática de consumo.

Certamente, ambas as condições - a do espectador e a do consumidor - contemplam o aspecto receptivo da moda. No entanto, gostaríamos de evidenciar o fato de que, se a moda conjuga recepção e produção, este último aspecto refere-se não apenas à atividade do estilista, daquele que concebe e constrói as peças do vestuário e os acessórios para os consumidores, mas igualmente à atuação que está presente na própria dinâmica do consumo contemporâneo, no qual o consumidor é seu próprio estilista.

Para dar conta do problema global da recepção no âmbito da moda, deveremos levar em consideração os fenômenos relacionados ao gosto (Parret) e aos mecanismos de distinção social que operam no plano imaginário (Bourdieu). Faremos isso oportunamente. Nesta comunicação, contudo, mesmo sem deixar de reconhecer que recepção e produção são dois aspectos indissociáveis da problemática estética, privilegiaremos a produção, tendo em vista o plano profissional e industrial, mas investigando também o papel de certa produtividade 
cotidiana, presente nas próprias práticas de consumo.

\section{0 estético e o artístico}

Como sabemos, o termo estética vem do grego aísthesis que significa sensação, sensibilidade. A idéia de sensibilidade, por sua vez, acolhe tanto a sensação, que remete a uma condição individual, quanto o sentimento, que pressupõe uma adesão comunitária. Desde já nos defrontamos, portanto, com uma situação ambígua, na medida em que envolve um modo de ser "afetado" que é individual, mas quer ser partilhado.

A estética se debruça sobre as respostas da sensibilidade e suas relações com o conhecimento, a razão e a ética. Nessa ampla investigação, as obras de arte tendem a ocupar um lugar de destaque, muitas vezes devido a certa confusão entre os termos "estética" e "poética". Não por acaso a discussão sobre o belo, a harmonia e a proporcionalidade nas artes tem sido um foco recorrente quando se fala em estética. A distinção entre esses termos deve ser, entretanto, uma das primeiras precauções metodológicas empreendidas pelos pesquisadores. Para tanto, basta lembrar, como sugere Pareyson (1989), que a estética tem um caráter filosófico e especulativo enquanto que a poética, pelo contrário, tem um caráter programático e operativo.

A partir dos anos 60, essa discussão ganha novos contornos com o desenvolvimento dos meios de comunicação e os produtos oriundos da chamada cultura de massa e a 'estética da comunicação' passa a ser incorporada na tentativa de compreensão desses produtos. Como observa Monclar Valverde, nesse registro podemos encontrar pesquisas fundadas na crítica ao imaginário e à ideologia, análises inspiradas na semiologia, na semiótica, na teoria da informação, nos estudos culturais, na psicanálise, bem como abordagens sobre as novas condições de recepção tendo em vista as poéticas baseadas nos meios de comunicação. Em todas elas, ressalta o autor, o aspecto estético é negligenciado. Por isso mesmo é preciso não apenas analisar esses produtos e criticálos, mas encarar a relação da problemática estética com a experiência ordinária.

(...) uma estética da comunicação deve ser algo mais amplo do que o estudo das interações verbais ou a análise poética das 'linguagens' contemporâneas. (...) O que se exige, portanto, é o desenvolvimento de um modo de abordagem em que os aspectos pragmático, plástico, semântico e sociotécnico sejam igualmente considerados, segundo os padrões da experiência contemporânea (Valverde, 2003, p.9).

O reconhecimento do cotidiano, sobretudo na chave de uma estética da comunicação, tem sido desenvolvido sob muitas perspectivas. Entre elas, mencionamos brevemente a abordagem de Hans Ulrich Gumbrecht, desenvolvida no texto "Pequenas crises: experiência estéti- ca nos mundos cotidianos" (2006) em que ele assegura a possibilidade da experiência estética no cotidiano, sob a condição de que esta será sempre uma exceção e por isso mesmo é preciso determinar as condições excepcionais que a tornam possível. Ele chega mesmo a firmar que: "Uma vez que ela se opõe ao fluxo da nossa experiência cotidiana, os momentos de experiência estética se parecem com pequenas crises" (p. 51). Ora, esse caráter de excepcionalidade sugere um afastamento do que é comum, do que é ordinário e nesse sentido parece, mais uma vez, reiterar uma concepção estética próxima à teoria da arte, como é sugerido nas considerações finais do seu texto.

Do nosso ponto de vista, reivindicar o espaço do cotidiano como terreno para a experiência estética significa apenas reconhecer a amplitude que a constitui, qual seja, o fato de que a estética não diz respeito apenas a uma ciência do belo ou a uma filosofia das artes, como determinou Baumgarten (quando cunhou a estética enquanto disciplina), mas que ela diz respeito a nossa sensibilidade e, portanto, ao nosso corpo, a nossa percepção. Podemos experimentar o sublime, o êxito, a consumação no nosso dia-a-dia e não apenas em situações extraordinárias... É disso que Dewey parece falar.

A distinção que ele estabelece entre o estético e o artístico, no texto "Tendo uma experiência", é bastante significativa e nos auxilia a não conceber o estético como sinônimo de artístico, embora percebendo as aproximações entre ambos. O autor observa que, em geral, a arte envolve um processo de fazer, de operar, uma intervenção sobre uma materialidade física. "Já a palavra 'estética' refere-se (...) à experiência enquanto apreciativa, perceptiva e agradável. Denota o ponto de vista do consumidor, mais do que do produtor" (1974, p.256).

No entanto, pondera ele, essa distinção não implica uma separação, pois a perfeição na execução necessita daqueles que percebem e gozam o produto executado; o produtor só concebe sua obra como finalizada quando se põe na condição de espectador. É nesse sentido que Dewey afirma: "a arte une as mesmas relações de fazer e padecer" (id., ibid., p.257).

O processo da arte na produção está relacionado organicamente com o estético na percepção (...). Até que o artista esteja satisfeito com a percepção do que está fazendo, continua formando e reformando. O fazer chega a um fim quando seu resultado é experimentado como bom - e essa experiência vem não por mero juízo intelectual e externo, mas na percepção direta. (...) Tal sensibilidade dirige também seu fazer e seu obrar (id., ibid., p.258).

É nesse sentido que Pareyson, na sua teoria da formatividade, insiste em enfatizar o processo e não o resultado da obra. Ao acentuar a relação entre o artista e sua arte, o autor ilumina o fato de que, ao produzir, o autor 
produz também seu modo de produzir, seu estilo, num diálogo constante com a matéria prima. Nessa perspectiva, o artista desce do pedestal da pura inventividade e assume também a condição de padecimento, ao se deixar conduzir pela obra.

Conforme Pareyson, "o processo artístico é caracterizado pela contemporaneidade de invenção e execução, e pela co-presença de incerteza e orientação, e é guiado pela teleologia interna do êxito, isto é, pela dialética de forma formante e forma formada" (1989, p.142).

Ao associar-se à filosofia de Dewey, que se preocupa com o caráter uno de toda experiência completa, Pareyson, assim como ele, enfatiza justamente o processo artístico como algo orgânico, cuja trajetória inclui gestação, incubação, nascimento, crescimento, maturação. Nas palavras do autor: "A obra inclui em si o processo da sua formação no próprio ato que o conclui, e o processo artístico consiste precisamente no acabar, no levar a termo, no fazer amadurecer: em suma, no perficere" (id., ibid., p. 147).

\section{Moda e artisticidade}

Quando o estilista Issey Miyake apresenta, em 1963, em seu espetáculo "A Poem of Cloth and Stone", a vestimenta como 'criação visual' e 'ferramenta funcional', reintroduz a questão: moda é arte? Muitos estilistas afirmam que sim, mas alguns insistem em dizer que não. Diante de tal polêmica, considera-se que talvez a resolução do problema passe por um deslocamento do ponto de vista, que deve pôr em relevo outra questão: existe na moda uma dimensão de artisticidade?

Por muito tempo, descartou-se a possibilidade de se pensar a moda como um campo artístico, devido ao argumento de que antes de tudo a moda é algo da ordem do funcional, servindo para cobrir o corpo. Ora, esta é uma objeção muito reducionista, pois já se demonstrou que o funcional também pode ser criativo e, porque não, artístico. Em Mode et Société (1992), Quentin Bell argumenta que muitos dos seus contemporâneos rejeitavam sua preocupação em pensar certos artigos da moda como arte, acionando um discurso pautado na funcionalidade, em contraposição à pura contemplação.

(...) eu considerava que uma teoria verdadeiramente pertinente devia ser aplicável a todas as formas de artes visuais e não apenas a uma ou outra entre elas. Ela devia poder englobar não apenas a paisagem e o quadro de caráter narrativo, mas também os chapéus e os sapatos. Aos olhos dos meus amigos marxistas, eu estava errado. Os chapéus e os sapatos, me diziam eles, não são obras de arte; e quando eu lhes dizia que uma criação de moda de Pisanello ou um saleiro de Cellini eram belos e obras de arte, assim como os bibelôs encontrados nas tumbas (...), eles retorquiam que estes eram exceções (...) (Bell, 1992, pp. 206-207).
Diretamente envolvidos nesta polêmica, outros estilistas opinaram sobre o estatuto do seu métier, como o fez Coco Chanel, ao afirmar que a moda não é uma arte, mas sim uma profissão como outra qualquer e que o fato da arte se servir da moda, já é uma glória para esta última. Para a estilista, um vestido não é nem uma tragédia, nem um quadro; é uma charmosa e efêmera criação, não uma obra de arte eterna, pois a moda deve morrer e morrer rápido, para que o comércio possa viver. Tributária ainda de uma ética cristã, outra linha de reflexão, pautada na distinção entre corpo e alma, estipula que a atenção voltada ao corpo é prejudicial à saúde da alma e considera toda atividade que se encontra relacionada à ornamentação, ao embelezamento, supérflua, menor, secundária.

\section{0 fato de reconhecer a} especificidade da arte (que é ser "formatividade pura") não nos autoriza a desconsiderar que existe uma dimensão de artisticidade nas atividades humanas em geral.

Assim, a figura do costureiro não tinha muito reconhecimento unânime, apesar de ser endeusada por alguns. Na prática, o que se observa é que, desde o final do século XIX, o costureiro ocupa um espaço cada vez mais importante. E sua importância só tende a crescer. A partir dos anos 70, com a proliferação do prêt-à-porter, o personagem criador-estrela é reforçado através da mídia, numa tentativa de recuperar certo 'glamour' em torno do universo da moda, que havia sido relativizado com a queda do poderio da Alta Costura.

Os jovens estilistas começam a investir numa modaespetáculo, multimídia, transformando os desfiles em grandes e surpreendentes cenas. Criadores como JeanCharles de Castelbajac, Thierry Mugler, Kenzo, JeanPaul Gaultier, Claude Montana, entre outros, são encorajados a realizar pesquisas cada vez mais arrojadas. Começa, assim, a produção de vestimentas-cênicas, impossíveis de portar. Inserido neste movimento, o próprio Issey Miyake, que tudo começou, organiza exposições em grandes museus de arte contemporânea, conferindo a suas criações um estatuto de objeto de museu. Nesta mesma direção, outros estilistas investem em criações de espaços que promovam uma certa sacralização da roupa, apresentando-a em instalações semelhantes àquelas utilizadas para a visualização de objetos de arte. “A 
moda dos criadores deve se merecer e, como obra de arte, fala apenas para um público iniciado!", assinala Muller. Mas não apenas os estilistas vão se aproximar da arte. No Brasil, por exemplo, o artista Hélio Oiticica exibe, em 1965, seus parangolés na exposição Opinião 65, no Museu de Arte Moderna do Rio de Janeiro e, em 1967, na Galeria Signals, em Londres. Os parangolés eram capas que as pessoas podiam vestir, participando, assim, ativamente da obra, interagindo com ela. Inspirados pelo movimento concretista, tanto Hélio Oiticica quanto Lygia Clark e Roberto Lanari constroem objetos vestíveis.

Moda e arte se entrelaçam: artistas participam de desfiles e catálogos de moda, criadores de moda são convocados para manifestações de arte contemporânea... Os dois mercados, em total sinergia, nutrem-se reciprocamente. "(...) no meio do consenso mais geral, a lua de mel entre arte e moda é um fenômeno internacionalmente celebrado, comentado, cada um encontrando sua parcela na cerimônia, a moda ganhando ares de nobreza suplementares e a arte conquistando o estatuto de uma dinâmica efêmera" (Remaury, 1997, p.59). As instalações, cada vez mais presentes nas bienais, confirmam esta tendência.

Mas e a moda? É ela produção de obras de arte?

Acreditamos que uma forma interessante de tentar responder a esta questão é adotar a perspectiva de Luigi Pareyson $(1989,1993)$ que reconhece a arte como uma atividade formativa. Dizer, pois, com Pareyson, que a arte é formatividade, é reconhecer que ela é invenção, sim, mas um tipo de inventividade que floresce no próprio ato de execução, no contato com a matéria prima, como assinalamos anteriormente. $\mathrm{O}$ artista produz, assim, concomitantemente, a obra e o seu próprio modo de produzir, ou seja, seu estilo. Nesse sentido, toda atividade em que se dá a produção do seu modo de produção deve ter reconhecida uma qualidade artística, uma artisticidade.

O fato de reconhecer a especificidade da arte (que é ser "formatividade pura") não nos autoriza a desconsiderar que existe uma dimensão de artisticidade nas atividades humanas em geral. É o que acentua essa passagem de Pareyson:

Entre a arte assim especificada e a arte que se estende a toda atividade do homem não há um abismo qualitativo ou uma solução de continuidade: há, antes, uma passagem gradual que, dos primeiros esboços oferecidos por aquele tanto de inventividade que é exigido pela atividade regulada e uniforme, alcança as mais altas e desinteressadas realizações da arte. A arte verdadeira e propriamente dita, não teria mais lugar se toda a operosidade humana não tivesse já um caráter 'artístico', que ela prolonga, aprimora e exalta (Pareyson, 1989, pp.37-38).

Essas reflexões acabam contribuindo para o esclareci- mento de um outro ponto: a constatação de que "toda obra de arte segue o plano e o padrão de uma experiência completa" (Dewey, 1974, p. 260). Ao reunir e articular certas formulações desses autores, somos forçados a reconhecer que a experiência estética não é apenas um tipo particular no campo geral da experiência humana, mas, sim, que "a experiência estética é o limite para o qual tende toda experiência e sem o qual ela não seria capaz de provocar efeitos e fazer sentido" (Valverde, 2007, p. 115).

Se as coisas são assim, podemos facilmente reconhecer certa dimensão de artisticidade em muitos empreendimentos tanto da Alta Costura como do prêt-à-porter, sem falar das customizações feitas pelo próprio usuário, ainda que elas respondam, também, a imperativos funcionais.

\section{0 estilo como modo de formar}

Em "Cortar é pensar: arte \& moda", o crítico de arte Germano Celant procura evidenciar a artisticidade presente na criação e produção da moda. Seu argumento tem como foco central o próprio ato de cortar, seja um papel (em se tratando de um molde), seja um tecido. Segundo o autor, o golpe de tesoura marca uma superfície que gera uma realidade; o corte dá significado e seu uso une artista e fotógrafo, designer e costureiro, pois cada um deles recorta uma forma no magma dos materiais: sejam elas tintas e bronze, película, tecido, lãs, metais, tela ou madeira. O autor defende, ainda, que o corte é a alma do vestir e do vestuário. "Talha o fio infinito de uma veste como simples contentor e retrato da figura humana, transformando-o em ato criativo, em linguagem construtora de novos objetos" (Celant apud Ceron \& Reis, 1999, p. 170). Ele nos convida a visualizar as iniciativas que corroboram sua visão, afirmando:

A roupa, com Judith Shea e Rosemarie Trockel, com Jana Sterbak e Jan Fabre, torna-se um engenho inquietante, autômato e manequim, estátua e máquina, figura de sonho e pesadelo, simulação delirante e cenografia paranóico-crítica. Já com Charles Le Dray, Oliver Herring, Wiebke Siem e Beverly Semmes transforma-se em vetor de um impulso fantástico e fascinante que reativa a lógica sonhada do vestuário como jogo e prazer, vida e espetáculo, máscara e travestimento (id.,ibid., p.176).

Ao buscarmos um exemplo contemporâneo de criação vestimentar cuja dimensão de artisticidade aparece com toda sua força e vigor, concentrando os comentários em torno da produção do prêt-à-porter, voltamos mais uma vez à figura do estilista Issey Miyake.

A criação de Miyake revela uma dupla preocupação: por um lado procura produzir as imagens a partir dos corpos que a vestimenta cobre e, por outro, introduz a imagem da figura e do corpo humano sobre a vestimenta 
(a esse respeito, o tecido - material ou suporte da roupa - pode ser definido como um plano esculpido, projetado sobre um volume em movimento no espaço). Observa-se, assim, uma intensa necessidade do estilista em sublinhar que a moda refere-se, sobretudo, ao corpo. A moda aparece, desse modo, como uma espécie de exercício de interpretação do corpo, e enquanto tal pode ser apreendida como uma representação do presente e mesmo uma reapresentação do corpo presente.

O corpo de uma mulher colado a uma escultura de Miyake torna-se uma vibração, uma sensação, um artifício que se vê intensificado pelo movimento e sua duração. Para além da moda, um desfile de Miyake toca uma dimensão religiosa, porque torna presente a função sagrada que apenas o ritual litúrgico confere habitualmente ao corpo. A vestimenta passa a significar esta verdade que o corpo é, no fundo, uma criação, uma aspiração, uma ficção divinas (Ribettes, 2001, p.117).

Amplitudes de volumes que deixam espaços vazios entre o corpo e a roupa, simplicidade moderna de formas desestruturadas, cores clássicas como brancos, cinzas e pretos, bem como cores luminosas e elétricas e os famosos plissados são as marcas do estilista que soube e continua a atender as necessidades do homem cosmopolita.

\section{0 consumidor contemporâneo, liberto das impositivas tendências, passa a ter um comportamento mais autoral em relação a suas escolhas.}

Quando Miyake depara-se com as formas e dinâmicas corporais e o diálogo entre o corpo e a roupa, investindo em pesquisas de novos materiais, explorando as possibilidades do tecido e de suas tessituras, e exibindo seu processo de criação e produção, ele descobre e aprimora seu modo de formar. E o exibe através de um estilo inconfundível, capaz de integrar de forma harmoniosa expressividade e funcionalidade. "Eu quero mostrar o processo e permitir que o próprio usuário participe dele", afirma.

\section{A dinâmica performativa do consumo}

Reconhecer o processo formativo do criador de moda é uma conquista. Mas não podemos esquecer que também o consumidor contemporâneo tem a possibilidade de "produzir", executar seu próprio look.
Sabe-se que na atualidade, o consumidor experimenta diversas tendências, preços e estilos... Neste cenário, podemos destacar três atitudes de consumo: a) a infidelidade em relação às marcas passou a se caracterizar como uma postura charmosa, b) a mistura de várias marcas é outra possibilidade de irreverência, e c) o abuso do uso de peças desprovidas do estatuto da marca tornou-se mais amplo e glamourizado. Tais posturas permitem uma verdadeira "liberdade de escolha" do consumidor que, em última instância, começa, ele mesmo, a experimentar a aventura e o fascínio da criação, tornando-se o seu próprio estilista.

Hoje se fala de consumo ativo, refletido, no qual o binômio preço/qualidade se revela como um dos critérios, ao lado de uma vontade lúcida e lúdica de singularidade. Como observa Christiane Mesquita (2006), "esta é uma época em que é possível definir a moda com frases como 'a gente é quem faz a moda' ou 'a moda não é roupa, é atitude'. O consumidor sente-se liberto das amarras das tendências e das marcas" (p. 142).

Esse processo vem se insinuando desde a década de 60, mas ganha certa radicalidade com a customização. Como nos relata a jornalista Érika Palomino (1999), a customização apareceu como reação à entediante logomania de fins da década de 90, quando tudo o que importava era a marca da grife. Vivia-se, assim, a glorificação do status e de uma moda calcada em ícones de riqueza.

A marca era o novo significante absoluto de identidade e prevalecia sobre o produto. O produto não era mais que meio de acesso à marca e a sua exibição social. Verdadeira insígnia social, bastava então que o produto fosse 'logotipado'. [...] os consumidores, por seu lado, não procuravam mais que uma panóplia ou uma etiqueta social a ser exibida (Lipovetsky e Roux, 2005, pp.119-120).

A customização, palavra oriunda da expressão inglesa custom made, que significa "feito sob medida", aparece justamente por conta da impossibilidade de se consumir marcas e, portanto, da vontade de brincar de "trabalhar" as peças, bordando, aplicando acessórios em busca de um look único. O verbo to customize significa "fazer ou mudar alguma coisa de acordo com as necessidades do comprador".

O consumidor contemporâneo, liberto das impositivas tendências, passa a ter um comportamento mais autoral em relação a suas escolhas. Ainda que não ignore inteiramente as propostas que são lançadas no mercado pela indústria da moda, o consumidor avalia, interfere, altera e brinca, em última instância, com os produtos, adaptando-os ao seu jeito de ser e aparecer.

Ao que parece, estilo é a palavra chave (...). Se se pode afirmar que o minimalismo fincado na perso- 
nalidade das marcas sugeriu, impulsionou, uma certa ausência suposta de estilos, ausência de signos; a produção "sob medida" seria o milagre do retorno do estilo, o renascimento dos estilistas, e o interessante é que desta vez parece que também o consumidor assume o posto e o estatuto de designer (Cidreira, 2005, p.76).

A personalização que assistimos hoje no universo da moda advém justamente da descoberta da possibilidade de 'modelização' do produto. Podemos afirmar que tal possibilidade é, na verdade, a radicalização da potencialidade que reveste todo "ato de vestir". O próprio fato de que a adoção de uma vestimenta se dá num corpo, de que esta presença corporal reveste a veste e que o corpo modela a forma que a roupa assume, exibe a dinâmica performativa do "ato de vestir".

Se reconhecer a dinâmica formativa do estilista é uma conquista, a do consumidor é uma vitória e tanto... No entanto, perceber e interpretar a dinâmica produtiva não é o bastante para tentar compreender como se estabelecem os mecanismos de adesão e identificação proporcionados e estimulados pelo universo da moda. A partir daqui será necessário reconhecer o caráter receptivo do consumidor, sua disposição a aderir a certas propostas expressivas e não a outras. Mas isto fica para outro texto... $\square$ FAMECOS

\section{NOTAS}

* Trabalho apresentado ao Grupo de Trabalho "Estética da Comunicação", do XVII Encontro da Compós, na UNIP, São Paulo, SP, em junho de 2008.

\section{REFERÊNCIAS}

BELL, Quentin. Mode et Société: essai sur la sociologie du vêtement. $2^{\mathrm{a}}$ ed. Trad. Isabelle Bour. Paris: Presses Universitaires de France, 1992.

CELANT, Germano. Cortar é pensar: arte \& moda In: PRADILHA, Céron; REIS, Paulo. Kant: crítica e estética na modernidade. São Paulo: Editora Senac SP, 1999.

CIDREIRA, Renata Pitombo. Os Sentidos da Moda. São Paulo: Annablume, 2005.

DEWEY, John. A Arte como experiência In: Os Pensadores. Trad. Murilo Leme. São Paulo: Abril S.A. Cultural e Industrial, 1974.

GUMBRECHT, Hans Ulrich. Pequenas crises: experiência estética nos mundos cotidianos In: GUIMARÃES, César; LEAL, Bruno e MENDONÇA, Carlos (Organização). Comunicação e esperiência estética. Belo Horizonte: Editora da UFMG, 2006.
ISSEY MIYAKE MAKING THINGS. Paris: Fondation Cartier pour l'art contemporaine, 1999.

LIPOVETSKY, Gilles e ROUX, Elyette. O Luxo Eterno: da idade do sagrado ao tempo das marcas. Trad. Maria Lucia Machado. São Paulo: Companhia das Letras, 2005.

MESQUITA, Christiane. A liquidação do estilo ou o luxo de gaguejar na própria língua In: KATHIA, Castilho e VILLACA, Nízia (Organizacao). O Novo Luxo. São Paulo: Editora Anhembi Morumbi, 2006.

PALOMINO, Érika. Babado forte: moda, música e noite na virada do século 21. São Paulo: Mandarim, 1999.

REMAURY, Bruno. Art a la mode In: ART PRESS. Art et Mode: attirance et divergence. Hors Série. Paris. $N^{\circ} 18$, 1997.

RIBETTES, Jean-Michel. Issey Miyake: L'incarnation et le triomphe du présent In: ART PRESS. Art et Mode: attirance et divergence. Hors Série. Paris. N 18, 1997.

PAREYSON, Luigi. Os problemas da estética. Trad. Maria Helena Nery Garcez. São Paulo: Martins Fontes, 1989.

PAREYSON, Luigi. Estética: Teoria da Formatividade. Trad. Ephraim Ferreira Alves. Petrópolis, Rio de Janeiro: Vozes, 1993.

VALVERDE, Monclar (Organização). As formas do sentido. Rio de Janeiro: DP\&A, 2003.

. Estética da comunicação. Salvador, Quarteto. 2007. 